\title{
24 USING ATTITUDES, BELIEFS, AND BEHAVIOURS TO SHAPE A CAMBODIAN MOTORCYCLE HELMET CAMPAIGN
}

doi:10.1136/injuryprev-2012-040590s.24

\footnotetext{
${ }^{1,2} \mathrm{D}$ Roehler, ${ }^{3} \mathrm{~S}$ Sann, ${ }^{4} \mathrm{P}$ Kim, ${ }^{5} \mathrm{M}$ Florian, ${ }^{5} \mathrm{M}$ Sidik, ${ }^{1} \mathrm{M}$. Ballesteros. ${ }^{1}$ Centers for Disease Control \& Prevention, USA; ${ }^{2}$ McNeal Professional Services, USA; ${ }^{3}$ Handicap International Belgium, Cambodia; ${ }^{4}$ Asia Injury Prevention Foundation, Cambodia; ${ }^{5}$ Asia Injury Prevention Foundation, Vietnam
}

Background As the number of motorcyclists in Cambodia increases, so do motorcycle-related injuries. Injuries decrease as helmet use increases. Campaigns addressing this issue will be more effective if they are based on prior knowledge and barrier of helmet use.

Aims/Objectives/Purpose To determine the prevalence of helmet use and reasons for non-use among motorcycle riders in Cambodia.

Methods We conducted helmet observations and roadside interviews in five Cambodian provinces.

Results/Outcomes Trained researchers observed helmet use for drivers of $71.4 \%$ at $9: 00,68.2 \%$ at noon, $62.7 \%$ at $17: 00$, and $47.8 \%$ at 19:00. For passengers, researchers observed rates of $6.6 \%$ at 9:00, $7.9 \%$ at noon, $6.3 \%$ at $17: 00$, and $4.7 \%$ at $19: 00$. Most drivers and passengers older than 16 years who reported that they regularly wear a helmet said they do so because it can save their life $(96 \%$ and $98 \%$, respectively). The most common reasons for not consistently wearing a helmet were: (1) 'factors that depend on where I drive,' (2) 'I forgot', (3) 'inconvenient/uncomfortable'. We found that $91 \%$ of riders get their road safety information from the television. Parents reported their children do not regularly wear a helmet because they are 'too young' $(37 \%)$ or they are 'riding close to home in their neighborhood' (17\%).

Significance/Contribution to the Field Helmet use varied greatly between drivers and passengers by time of day. As a result of these data, we have launch a television campaign focused on passengers and emphasising the importance of wearing a helmet anytime they are on a motorcycle. 